\title{
Impact of COVID-19 on Pain Medicine Fellowship Training
}

To the Editor

Typically, the fourth quarter of the academic year brings with it the excitement of impending graduation for pain fellows, along with their preparation for independent practice. The last few months are spent fine-tuning skills, creating one's own style of practice, and gaining confidence in the practice of pain medicine. Thus, an additional challenge amidst the COVID-19 pandemic is helping prepare fellows to advance to graduation in a restricted environment that limits their typical end of year activities.

Pain medicine is a multidisciplinary, multidimensional specialty. Fellowship training includes learning technical skills to perform delicate procedures, proper physical exam maneuvers, and the art of having difficult conversations. With creativity, distance learning, and collaboration all of these can continue on, in spite of, social distancing measures. And, while we all agree that nothing fully replaces hands-on training, there are still significant opportunities for remote learning. Thanks to improved technology, fellows can learn through online platforms. Interactive journal clubs, webinars, and lectures are possible via online webconferencing systems. And these opportunities do not have to be program specific. Through online collaboration, programs can pool resources and education may be multi-institutional. If logistical challenges arise, scheduled fellowship lectures can be recorded and a follow-up conference call arranged.

There is particular concern with regard to neuromodulation training. Recent 
graduating pain fellows reported deficits in spinal cord stimulation (SCS) education, identifying poor SCS case volume $(38.5 \%)$, the lack of SCS curriculum $(30.8 \%)$, and lack of faculty with SCS expertise $(23.1 \%)$ as important barriers to their projected future use of these procedures. ${ }^{1}$ An online neuromodulation curriculum called "Pain Rounds" may be a solution. Pain Rounds was developed based on a needs assessment of the national pain medicine fellowship program directors and focus groups with graduating pain fellows. The curriculum includes expert video interviews, cadaver lab demonstrations, content reviews, casebased discussions, and interactive "games" in which decision-making is tested". There are additional neuromodulation educational videos available through other platforms, including those from multiple pain medicine societies, which can be integrated into the fellowship didactic plan.

Thankfully, in addition to the above options, the field of pain medicine has recognized that current fellows will be seeking additional hands-on experience to supplement their fellowship year. To that end, preparations are underway to provide those opportunities. Through our pain medicine societies, in addition to our industry partners, additional cadaver lab and practical skills sessions will be available to interested individuals.

Lastly, and very importantly, fellows should identify mentors and colleagues in their practice and community that are accessible and with whom they are comfortable. These relationships will allow discussion of opportunities and challenges, and development of skills as confidence grows.

It is nearly universal among graduating fellows to feel some anxiety about independent practice without faculty oversight. Many will feel unprepared for that transition, even in a typical year. Commonly, the first few months as an attending are spent finding a comfort zone. The curtailed training of this year will likely heighten this feeling, especially for fellows who feel they have not done enough of certain procedures or surgeries. However, for the vast majority of fellows, they will have developed the core skills and techniques necessary to perform at an appropriate level. Learning how to apply those techniques in new or challenging circumstances is a lifelong endeavor as a pain physician, although with a steeper curve in early career stages. The field of pain medicine, including fellowship programs, national organizations, and industry, recognizes that this is a difficult and atypical situation, and will be working hard to ensure fellows and early practice physicians are comfortable and prepared for the next step.

Jonathan M Hagedorn $\odot,{ }^{1}$ Susan Moeschler, ${ }^{1}$ Timothy Furnish, ${ }^{2}$ Dawood Sayed, ${ }^{3}$ Shravani Durbhakula ${ }^{4}$

${ }^{1}$ Department of Anesthesiology and Perioperative Medicine, Mayo Clinic, Rochester, Minnesota, USA ${ }^{2}$ Department of Anesthesiology, University of California San Diego School of Medicine, La Jolla, California, USA

${ }^{3}$ Department of Anesthesiology, University of Kansas School of Medicine, Kansas City, Kansas, USA

${ }^{4}$ Department of Anesthesiology and Critical Care Medicine, Johns Hopkins School of Medicine, Baltimore, Maryland, USA

Correspondence to Dr Jonathan M Hagedorn, Department of Anesthesiology and Perioperative Medicine, Mayo Clinic Rochester, Rochester, MN 55905, USA; hagedorn.jonathan@mayo.edu

Twitter Jonathan M Hagedorn @jonhagedornmd

Contributors All authors contributed to the manuscript and agreed on the final version.

Funding This platform is funded through an unrestricted educational grant to Johns Hopkins University from industry; of note, it has been peerreviewed for content/bias, and industry has no control, voice, or ownership in the content produced.

Competing interests DS has been a consultant for Vertiflex, Abbott, Flowonix, Merit, Nevro, SPR, and Stimgenics and has stock in Flowonix, SPR, and Stimgenics.

Patient consent for publication Not required.

Provenance and peer review Not commissioned; internally peer reviewed.

This article is made freely available for use in accordance with BMJ's website terms and conditions for the duration of the covid-19 pandemic or until otherwise determined by BMJ. You may use, download and print the article for any lawful, non-commercial purpose (including text and data mining) provided that all copyright notices and trade marks are retained.

(c) American Society of Regional Anesthesia \& Pain Medicine 2021. No commercial re-use. See rights and permissions. Published by BMJ.

Check for updates

To cite Hagedorn JM, Moeschler S, Furnish T, et al. Reg Anesth Pain Med 2021;46:188-189.

Received 6 April 2020

Revised 9 April 2020

Accepted 13 April 2020

Published Online First 27 April 2020

Reg Anesth Pain Med 2021;46:188-189.

doi:10.1136/rapm-2020-101534

ORCID iD

Jonathan M Hagedorn http://orcid.org/0000-00031039-8166

\section{REFERENCE}

1 Pak DJ, Gruber J, Deer T, et al. Spinal cord stimulator education during pain fellowship: unmet training needs and factors that impact future practice. Reg Anesth Pain Med 2019;44:407-14. 